\title{
Reimplantation for anomalous right coronary artery
}

Juan B. Grau, MD, ${ }^{\mathrm{a}, \mathrm{b}}$ Kenza Rahmouni, MD, ${ }^{\mathrm{a}}$ Javier Castillo, MD, ${ }^{\mathrm{c}}$ Marc Ruel, MD, ${ }^{\mathrm{a}}$ and Gyaandeo Maharajh, MD, ${ }^{\text {a,d }}$ Ottawa, Ontario, Canada; Ridgewood, NJ; and Guaynabo, Puerto Rico

From the ${ }^{\mathrm{a} D i v i s i o n}$ of Cardiac Surgery, University of Ottawa Heart Institute, Ottawa, Ontario, Canada; ${ }^{\mathrm{b} D i v i s i o n}$ of Cardiothoracic Surgery, The Valley Hospital, Ridgewood, NJ; ${ }^{c}$ Hyspanic Valve Center, Guaynabo, Puerto Rico; and 'Division of Cardiovascular Surgery, Children's Hospital of Eastern Ontario, Ottawa, Ontario, Canada.

Disclosures: The authors reported no conflicts of interest.

The Journal policy requires editors and reviewers to disclose conflicts of interest and to decline handling or reviewing manuscripts for which they may have a conflict of interest. The editors and reviewers of this article have no conflicts of interest.

Received for publication Jan 20, 2021; accepted for publication Jan 22, 2021; available ahead of print Feb 2, 2021. Address for reprints: Juan B. Grau, MD, Division of Cardiac Surgery, University of Ottawa Heart Institute, 40 Ruskin St, Ottawa, Ontario, Canada, K1Y 4W7; and Cardiothoracic Surgery, The Valley Hospital, 223 N Van Dien Ave, Ridgewood, NJ 07450 (E-mail: grauju@valleyhealth.com and jgrau@ ottawaheart.ca). JTCVS Techniques 2021;7:226-8

2666-2507

Published by Elsevier Inc. on behalf of The American Association for Thoracic Surgery. This is an open access article under the CC BY-NC-ND license (http://creativecommons.org/licenses/by-nc-nd/4.0/).

https://doi.org/10.1016/j.xjtc.2021.01.033

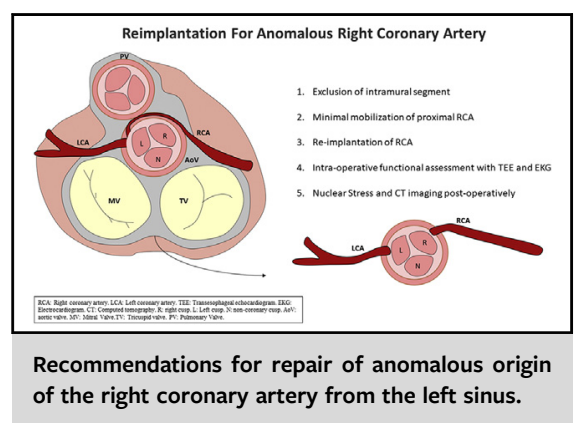

CENTRAL MESSAGE

Coronary reimplantation is a safe procedure to correct an anomalous origin of the right coronary artery. It should be used whenever possible, as it restores normal anatomic and physiologic conditions

See Commentaries on pages 229 and 231.
Anomalous aortic origin of coronary arteries is the second most common cause of sudden death after hypertrophic obstructive cardiomyopathy. ${ }^{1}$ It occurs when the left, right, or both coronary arteries do not originate from their respective sinuses of Valsalva. Anomalous origin of the right coronary artery (AAORCA) is significantly more common than the left-sided anomalous aortic origin of coronary arteries. ${ }^{2}$ Patients with signs of myocardial ischemia should be referred for surgical intervention. ${ }^{1}$

Several surgical techniques to treat AAORCA have been described, including unroofing, pulmonary artery translocation, coronary artery bypass grafting, and coronary translocation and reimplantation. The latter technique involves reattaching the anomalous coronary to its respective sinus of Valsalva to restore normal physiology. Results from surgical series with right coronary artery (RCA) reimplantation have shown promising outcomes. ${ }^{2-4}$ We have adopted this operation at out institution, and here we describe our technique.

\section{SURGICAL TECHNIQUE}

After median sternotomy and initiation of cardiopulmonary bypass, the anomalous RCA is identified and dissected up to its takeoff from its intramural portion (Figure 1 and Video 1), a length of 1.5-2 cm. The next step involves selection of the site of reimplantation, either high in the right coronary sinus of the aortic root or on the anterior surface of the proximal ascending aorta to avoid undue kinking; we recommend that this be done with the heart beating.

At this time, marking of the RCA superior aspect is done to maintain proper orientation of this vessel and avoid rotation before implantation. Next, the heart is arrested with antegrade cold blood-based cardioplegia. A transverse aortotomy is performed $2 \mathrm{~cm}$ above the sinotubular junction. At this time the most proximal aspect of the RCA as it emerges from the aortic root is identified and transected. The residual stump is then oversewn with 6-0 Prolene. A neo-ostium is then created with an aortic punch (Figure 2 and Video 1). The proximal end of the RCA is now spatulated for a length of 7-8 $\mathrm{mm}$.

Construction of the proximal anastomosis starts by positioning the heel of the spatulated RCA toward the atrioventricular groove. This anastomosis is completed with 6-0 Prolene using a parachuting technique. This is followed by 2-layer closure of the aortotomy. A final injection of warm cardioplegia is given through the newly reimplanted RCA. During this injection, assessment of the 

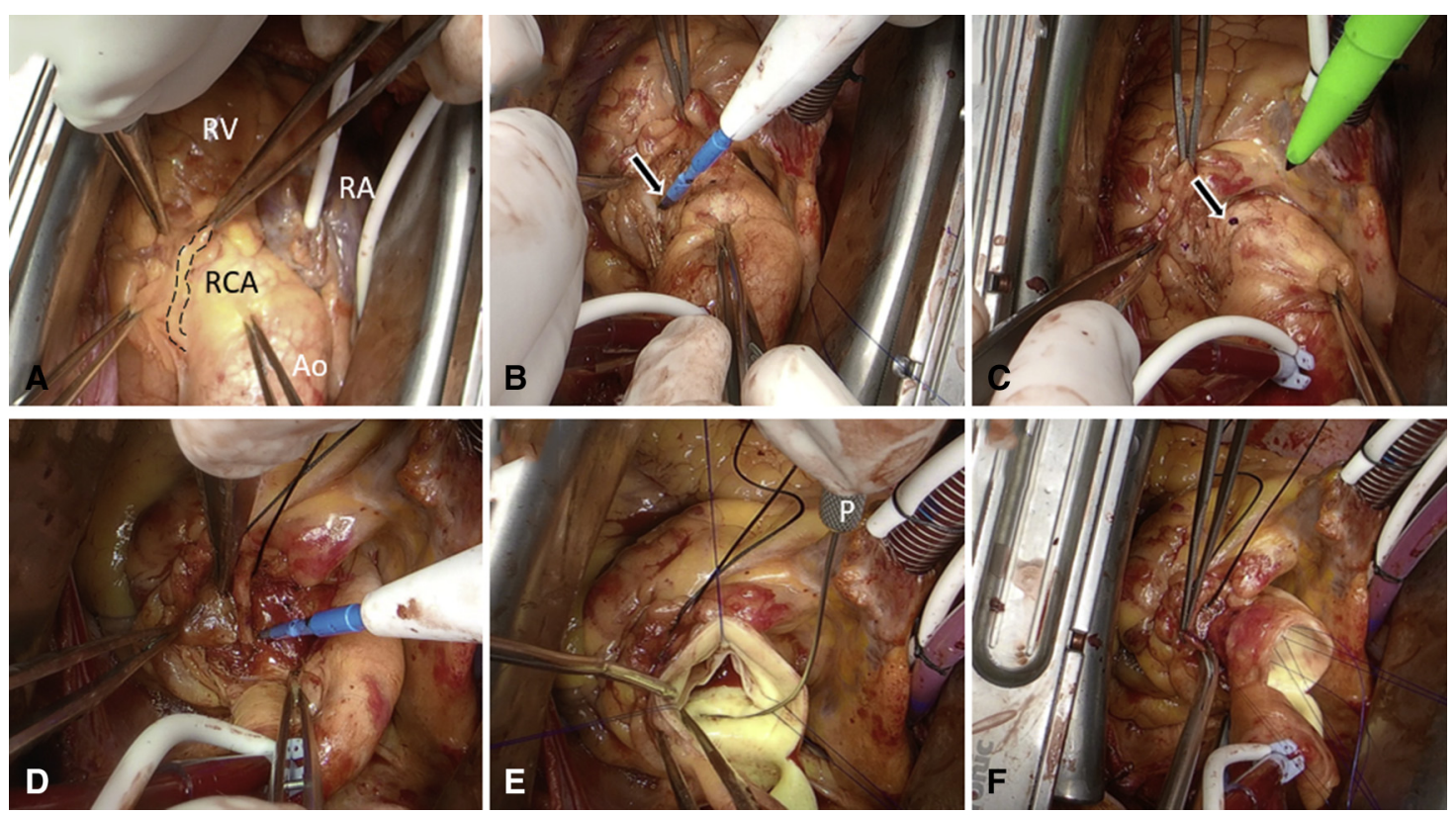

FIGURE 1. Intraoperative images showing the steps in right coronary artery $(R C A)$ dissection. A, Identification of the RCA showing its anomalous origin and trajectory (dashed line). It originates in the left coronary sinus and courses anteriorly between the aorta and pulmonary arteries. B, RCA dissection using electrocautery (arrow) and nontraumatic coronary forceps. C, Marking of the reimplantation site while on-pump beating with good filling (arrow). The selected reimplantation site should account for the length of the anomalous segment of the RCA, and surgeons should avoid selecting a site that is too low, as it may cause undue kinking of the RCA. D, Completed mobilization of the RCA over approximately $1.5-2 \mathrm{~cm}$. E, Confirmation of the chosen reimplantation site with visualization of the internal aspect of the aortic root anatomy. Internal inspection shows the anomalous aortic origin of the RCA and its relationship with the aortic valve commissures. The coronary probe demonstrates that the intramural segment courses below the left-right aortic valve commissure. F, Proximal ligation and transection of the junction between the intramural and proximal RCA using 6-0 Prolene. $R V$, Right ventricle; $R A$, right atrium; $A o$, aorta; $P$, probe.

RCA flow dynamics with Doppler ultrasound is performed. Finally, the heart is unclamped and deaired.

Right ventricular function is cautiously examined by visual inspection and transesophageal echocardiography; the electrocardiogram tracing is also carefully monitored. Patients undergo nuclear stress testing and cardiac computed tomography angiography before discharge. They are then allowed to return to unrestricted physical activities at 6-8 weeks postoperatively.

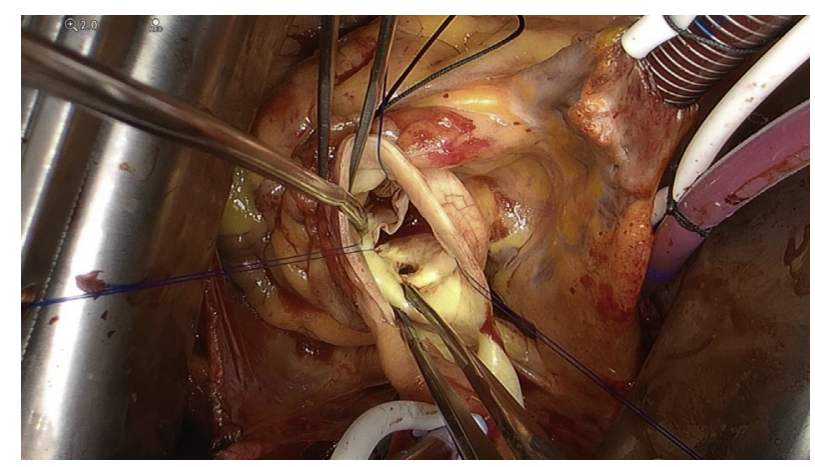

VIDEO 1. Surgical technique for reimplantation of the anomalous origin of right coronary artery from the left coronary sinus. Video available at: https://www.jtcvs.org/article/S2666-2507(21)00117-6/fulltext.

\section{DISCUSSION}

Here we share our recommendations to ensure optimal results following RCA reimplantation. Mobilization of the RCA for $1.5-2 \mathrm{~cm}$ is necessary to create a tension-free anastomosis and spares the most important proximal branches of the RCA.

Because of their abnormal morphology, AAORCAs tend to be longer than normal RCAs and often need to be reimplanted higher in the right coronary sinus or in the very proximal ascending aorta. ${ }^{5}$ RCA kinking following reimplantation is a pitfall of this operation that can result from selecting a reimplantation site that is too low in the right coronary sinus. To avoid this complication, we recommend selecting the site of the proximal RCA anastomosis while the heart is beating and on cardiopulmonary bypass. Confirmation of correct positioning of the neo-ostium in relation to the aortic valve commissures is essential and is achieved most safely by performing an aortotomy to allow for direct visualization of the aortic valve. A meticulous construction of the anastomosis with the heel oriented toward the natural trajectory of the RCA is of paramount importance. This is achieved by using the atrioventricular groove as the reference point to orient the heel of this proximal anastomosis using a takeoff angle of $\sim 30^{\circ}$. 

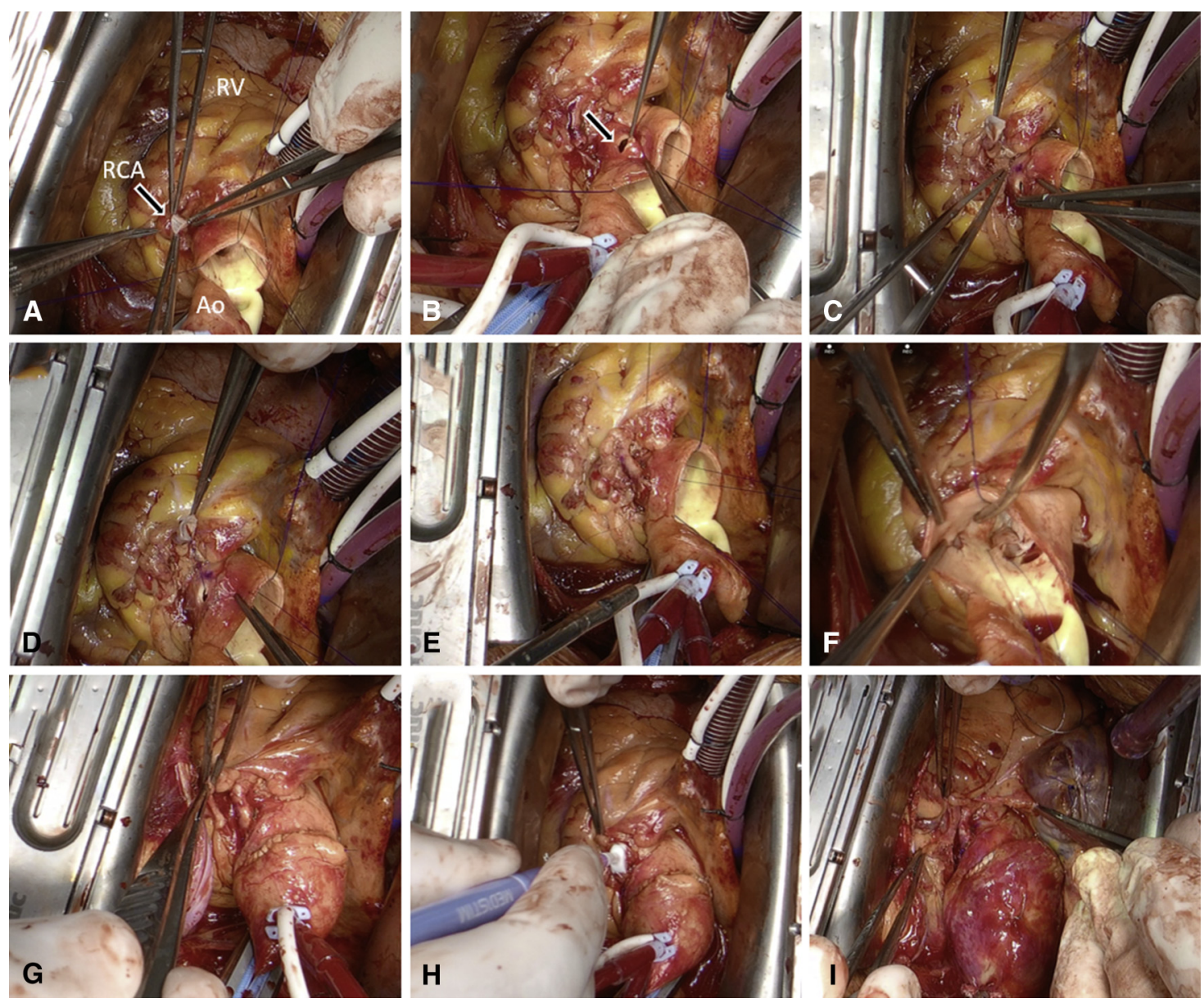

FIGURE 2. Intraoperative images showing right coronary artery $(R C A)$ reimplantation. A, Bevel opening on inferior aspect of the RCA with microscissors (arrow). B, Creation of the neo-ostium site with an aortic punch (arrow). C, Orientation of RCA anastomosis with heel directed toward the atrioventricular groove. D, Completion of the proximal anastomosis with 6-0 Prolene using the parachuting technique. E and F, Completed anastomosis seen from the epicardial (E) and endocardial (F) surfaces. This step is followed by closure of the aortotomy with 2 layers of 4-0 Prolene (not shown). G, Assessment of hemostasis and unclamping. H, Doppler flow measurement with cardioplegia administration. I, Evaluation of anastomoses off cardiopulmonary bypass. $R V$, Right ventricle; $A o$, aorta.

Moreover, we recommend that the procedure be followed by careful intraoperative evaluation of RCA flow with Doppler, transesophageal echocardiography for right ventricular function, and electrocardiography for signs of ischemia. Before discharge, all patients should undergo nuclear stress imaging and a postoperative computed tomography angiogram to assess the new RCA course and patency.

In summary, RCA reimplantation is a straightforward operation that restores normal anatomic and physiologic conditions and provides a solution for most morphological anomalies found in AAORCAs, including slit-like ostium, acute angle takeoff, and intramural and interarterial course. For this reason, every surgeon should become familiar with this approach for patients with AAORCA.
The authors would like to thank Dr Lara Gharibeh for her help in making the central figure.

\section{References}

1. Brothers JA, Frommelt MA, Jaquiss RDB, Myerburg RJ, Fraser CD Jr, Tweddell JS. Expert consensus guidelines: anomalous aortic origin of a coronary artery. J Thorac Cardiovasc Surg. 2017;153:1440-57.

2. Law T, Dunne B, Stamp N, Ho KM, Andrews D. Surgical results and outcomes after reimplantation for the management of anomalous aortic origin of the right coronary artery. Ann Thorac Surg. 2016;102:192-8.

3. Cubero A, Crespo A, Hamzeh G, Cortes A, Rivas D, Aramendi JI. Anomalous origin of right coronary artery from left coronary sinus-13 cases treated with the reimplantation technique. World J Pediatr Congenit Heart Surg. 2017;8:315-20.

4. Gaillard M, Pontailler M, Danial P, de Bellaing AM, Gaudin R, du PuyMontbrun L, et al. Anomalous aortic origin of coronary arteries: an alternative to the unroofing strategy. Eur J Cardiothorac Surg. 2020;58:975-82.

5. Saleem S, Syed M, Elzanaty AM, Nazir S, Changal K, Gul S, et al. Interarterial course of anomalous right coronary artery: role of symptoms and surgical outcomes. Coron Artery Dis. 2020;31:538-44. 